Original Article

\title{
Pulmonary Function Tests Vary in Different Cities of Baluchistan, Pakistan
} Mobin Ahmed ${ }^{1}$, Sheeba Faryal ${ }^{2}$ \& Khalid Sheikh ${ }^{2}$

1. Asian Institute of Medical Sciences (AIMS)

2. Liaquat University of Medical \& Health Sciences (LUMHS)

Corresponding Author: dr.mubeen41@gmail.com

\begin{abstract}
Objective The objective of this study was to measure the pulmonary function tests in population living in Baluchistan, Pakistan. Method The study area was conducted in province of Baluchistan, which is the largest province of Pakistan. A cross sectional study has been carried out to observe Normal lung functioning in residents of Baluchistan followed by a randomized Sample selection of individuals from five strata of Baluchistan. Brief detail was told to the subjects that why the test were being done to make their cooperation better. Written consent from all subjects was taken after explaining the experimental procedure. Results The results of present study, as shown in (Table 4.2.1) shows significance difference on the comparison of FVC, FEV1, PEFR and FEV1 IFVC the mean value of FVC, FEV1, PEFR and FEV1 $\mathrm{FVC}$ in Baluchistan with the standard Chamanern mean values according to their gender, age and height.it was found 3.46, 2.56, 379.8 and 0.741 on average with an standard deviation of $0.21,0.14,46.75$ and 0.043 respectively. Conclusion It is concluded that FVC, FEV1, PEFR, and FEV1/FVC have significant differences in mean, the means of Baluchistan city were less than a per standard Chamanern mean values, it also gives significant differences within Citys of Baluchistan city as spirometric values exclusively depends upon body shape, chest size, BMI, Age, environment, life style, anatomical differences, altitude and lung development.
\end{abstract}

\section{Keywords}

Pulmonary Function Tests, Baluchistan, Spirometry

\section{Introduction}

The differences observed in various lung function tests depend on age, sex, height, physical activity, and smoking, besides socio-economic status, environmental conditions, altitude and ethnicity. Spirometry has an established role in understanding various normal and pathological functions of respiratory system and thereby plays an important role in screening, diagnosing and monitoring respiratory functions in different conditions and disease states affecting lungs. ${ }^{1}$ Further, Spirometry is a helpful tool for evaluation of breathing reserve and exercise tolerance to determine physical fitness in normal people ${ }^{2}$ pulmonary function tests
(PFTs) can identify respiratory abnormalities such as chronic obstructive pulmonary diseases that might otherwise be overlooked.

Physicians cannot identify obstructive or restrictive patterns of respiratory diseases reliably from history and physical examination alone ${ }^{3,4}$. Lung function tests in addition can quantify severity and presence of reversible component of airflow obstruction. Further such testing is essential in the diagnosis and the management of bronchial asthma.6 PFTs are also used when more than one explanation is there for patient's symptoms, evaluation of fitness, etc. There is little evidence to support a 
policy of screening the general population with spirometry. Screening and monitoring are appropriate for cigarette smokers and people exposed to agents known to cause lung injury, such as, asbestos who are at risk of developing lung disease.

In Framingham study, decrease in vital capacity was a better predictor of heart failure and recovery than symptoms and signs ${ }^{5}$ in a large Middle-Turbat population study observed that parameters tend to increase with age before 20 years while after 20 years these show a decline. In healthy Pakistani adults it was observed that the height and age were always found to be important predictors of lung function parameters ${ }^{6}$. Previous studies have indicated that lung volumes in healthy, normal Pakistani adults are smaller than measurements reported in comparable healthy European populations; in order to confirm these findings and to examine the relationship of maximal expiratory flow rates to lung volumes. It was found that gender had no effect on mean values of $\mathrm{FVC} \%$ and FEV1\%. This is in contrast to other researchers who have reported significantly higher values of baseline pulmonary function in males ${ }^{7,8}$ Such differences are reported to be present in all age groups, including adults, adolescents, children, and infants.

In addition, it has been suggested that environmental factors, including nutrition, physical activity, air pollution and socioeconomic status, can affect lung function ${ }^{9}$ In fact, the spirometric values in a group of high altitude residents in a Himalayan region of Nepal were found to be larger than Caucasians ${ }^{10}$. There were altitude-related changes in spirometric values in a group of mountaineers when spirometry was performed at the sea level and at different altitudes ${ }^{11}$. Thus, it is important to have reference values from healthy populations for comparison. The American Thoracic Society (ATS) recommend the use of the third National Health and Nutrition Examination Survey (NHANES III) reference ${ }^{12}$ for interpreting spirometry results. This dataset is one of the few references spanning childhood and adulthood, which is also nationally representative and generalizable. The objective of this study was to measure the pulmonary function tests in population living in Baluchistan, Pakistan.

\section{Methodology}

The study area was conducted in province of Baluchistan, which is the largest province of Pakistan. A cross sectional study has been carried out to observe Normal lung functioning in residents of Baluchistan followed by a randomized Sample selection of individuals from five strata of Baluchistan.

\section{Inclusion Criteria}

1. All individuals (adults) from both genders males and females should be in the age range of $18-50$.

2. They must had spent at three years in Baluchistan.

3. Only non- smokers must be preferred.

4. All participants must have BMI $<25$.

\section{Exclusion Criteria}

1. Individuals who don't belong to Baluchistan.

2. Patients with respiratory diseases are excluded.

3. Anatomical differences like oronasal, neuromuscular and skeletal.

4. Mentally challenged subjects.

5. All hawkers, rickshaw drivers, police constables and road side workers are excluded.

2500 samples were selected from each strata of Baluchistan. Brief detail were told to the subjects that why the test were being done to make their cooperation better. Written 
consent from all subjects was taken after explaining the experimental procedure.

\section{Results}

Table 1 showing the further classification of distribution of subjects into five different regions \& demographics.

\begin{tabular}{ll}
\hline Gender & Frequency \\
\hline Female & 2639 \\
\hline Male & 2734 \\
\hline Total & 5373 \\
\hline City & Frequency \\
\hline Quetta & 1151 \\
\hline Khuzdar & 895 \\
\hline Turbat & 1194 \\
\hline Hub & 892 \\
\hline Total & 1241 \\
\hline Age Groups & 5373 \\
\hline$\leq 18$ Years & Frequency \\
\hline $19-20$ & 937 \\
\hline $21-22$ & 982 \\
\hline $23-24$ & 1372 \\
\hline$\geq 25$ Years & 1124 \\
\hline Total & 958 \\
\hline
\end{tabular}

Table 2 Comparison of FVC, FEV1, PEFR and FEV1 IFVC with in Baluchistan Cities.

\begin{tabular}{lllll}
\hline \multicolumn{5}{c}{ Tests of Normality } \\
\hline & $\begin{array}{c}\text { Kolmogorov- } \\
\text { Smirnova }\end{array}$ & Shapiro-Wilk \\
& Statistic & $\begin{array}{c}\text { p- } \\
\text { value }\end{array}$ & Statistic & Sig. \\
\hline FVC & 0.092 & $<0.01$ & 0.901 & $<0.01$ \\
\hline FEV1 & $\mathbf{0 . 0 8 4}$ & $<\mathbf{0 . 0 1}$ & $\mathbf{0 . 9 3 6}$ & $<\mathbf{0 . 0 1}$ \\
\hline PEFR & 0.051 & $<0.01$ & 0.991 & $<0.01$ \\
\hline FEV1\FVC & $\mathbf{0 . 0 9}$ & $<\mathbf{0 . 0 1}$ & $\mathbf{0 . 8 7 5}$ & $<\mathbf{0 . 0 1}$ \\
\hline${ }^{*}$ p $<0.05$ considered as significant \\
\hline \multicolumn{6}{c}{} \\
\hline
\end{tabular}


Table 3 comparison on the mean values of FVC, FEV1, PEFR, and FEV1/FVC, across the all Cities of Baluchistan.

\begin{tabular}{lllll}
\hline City & $\begin{array}{l}\text { Mean } \\
\text { FVC }\end{array}$ & $\begin{array}{l}\text { Mean } \\
\text { FEV1 }\end{array}$ & $\begin{array}{l}\text { Mean } \\
\text { PEFR }\end{array}$ & MEV1/FVC \\
& & & & \\
\hline Quetta & $\mathbf{3 . 3 9}$ & $\mathbf{2 . 5 5}$ & $\mathbf{3 7 4 . 2}$ & $\mathbf{0 . 7 4}$ \\
\hline Khuzdar & $\mathbf{3 . 4 6}$ & $\mathbf{2 . 5 7}$ & $\mathbf{3 8 1 . 6}$ & $\mathbf{0 . 7 3}$ \\
\hline Turbat & $\mathbf{3 . 4 1}$ & $\mathbf{2 . 5 1}$ & $\mathbf{3 8 0 . 9}$ & $\mathbf{0 . 7 4}$ \\
\hline Chaman & $\mathbf{3 . 4 8}$ & $\mathbf{2 . 5 6}$ & $\mathbf{3 7 8 . 5}$ & $\mathbf{0 . 7 2}$ \\
\hline Hub & $\mathbf{3 . 4 3}$ & $\mathbf{2 . 5 5}$ & $\mathbf{3 7 3 . 3}$ & $\mathbf{0 . 7 5}$ \\
\hline
\end{tabular}

\section{Discussion}

Pulmonary function test (PFT) has assumed an essential role in epidemiological studies investigating the incidence, natural history and causality of occupational and environmental lung disease ${ }^{13}$.Prevalance of COPD is increasing in developed countries and establishing a common death ground globally, the disease however characterized by a gradual progressing, irreversible air flow limitation caused by chronic inflammation in the bronchioles. If Spirometry is performed COPD can be diagnosed in the initial phase. In this study we determine the spirometric reference values (FEV1, FVC, FEV1/FVC and PEFR) of adult population of Baluchistan aged between $18-50$ years amongst locals. The results of present study, as shown in (Table 4.2.1)shows significance difference on the comparison of FVC, FEV1, PEFR and FEV1\FVC the mean value of FVC, FEV1, PEFR and FEV1 IFVC in Baluchistan with the standard Chamanern mean values according to their gender, age and height.it was found 3.46, $2.56,379.8$ and 0.741 on average with an standard deviation of $0.21,0.14,46.75$ and 0.043 respectively while in the Chamanern the mean FVC, FEV1, PEFR and FEV1 $\mathrm{LFVC}$ was 3.96, 3.40, 487.8, 0.086 with an standard deviation of $0.86,0.62,78.23,0.033$ however mean FVC was lesser in Baluchistan as compared to Chamanern mean $\mathrm{FVC}$ with ratio value of FVC $91.06 \%$ while mean FEV1 was lower in Baluchistan as compared to Chamanern mean FEV1 with ratio value of FEV1 77.52\% mean PEFR in Baluchistan not as per standard to Chamanern mean PEFR with ratio value of PEFR $79.9 \%$ and mean FEV1/FVC was lower in Baluchistan compared to Chamanern meanFEV1/FVC.

With the ratio value of FEV1\FVC $85.94 \%$ however another variable that has been observed to possess an important position in pulmonary functions is racial groups ${ }^{14}$. Normal Values for FVC and FEV1 in many of Asian population are found to be low than white population. As shown in (Table 2) the comparison of FVC, FEV1, PEFR and FEV1 $\backslash F V C$ with in Baluchistan, the maximum mean value of $3.4671 \mathrm{FVC}$ was found in Khuzdar region, for FEV1 the maximum value of 2.5716 was found in Turbat region, the maximum value of PEFR 38.49 was found in Khuzdar region and for $\mathrm{FVC} 1 / \mathrm{FVC}$ the maximum value 0.743 was in Turbat region of Baluchistan city our data shows difference value are due to different ethnic groups while we cannot assume the normality of data and non-parametric testing should be done for 
comparison across the Citys of Baluchistan. When we calculate the multiple comparisons of mean values made on FVC, PEFR and FEV1/FVC, across all Citys of Baluchistan city shows the significance mean differences between two Cities. Since FEV1 was same on average across all the Citys therefore, no multiple comparisons were made on it. Whilst previous research report that in a large Middle-Turbat population parameters tend to increase with age before 20 years while after 20 years these show a decline. In healthy Pakistani adults, it was observed that the height and age were always found to be important predictors of lung function parameters. However, height and body stature, variation in thoracic influence Spirometric volumes and it also affecting pulmonary function other Physiological factors effecting spirometry the respiratory system undergoes structural changes with as the age progresses; these changes include chest wall and thoracic spine deformities, that can impair lung and respiratory compliance eventually leads to enhance the work of breathing. The dilation of air spaces i.e senile emphysema as lung parenchyma losses connective tissue is also a common finding with age related decline in respiratory muscles strength and BMI has significant effect on all lung volumes and principally FRC and ERV ${ }^{15}$, besides age and height recent study revealed that BMI is considered as independent variable. It is related to decrease in longitudinal FEV1 and FVC in adults, and has its effect on ventilatory function, independent of age ${ }^{16}$. BMI and respiratory function alteration has been seen significantly in both males and females while ventilatory function of humans depends upon height, age and gender ${ }^{17}$, while the most important corresponded variants to lung volume are body size and standing height, in children and adolescent's lung growth retards due to increase in standing height during growth surge.
There is an alteration in the relationship between lung volume and height during adolescence with the help of allometric relationships between stature and lung volumes on contrary FEV1/FVC\% indices decrease with respect to height and increase with age and is observed higher in females ${ }^{18}$. In males, it has been found that FVC and FEV1 reach to an utmost level at the age of 21 to 22 years then declines with rise in age, but in females no such real surges has been reported within these ages ${ }^{19}$. From clinical prospective it has been observed, that FEV1 is one of the excellent predictor of cardiovascular and pulmonary morbidity and mortality. On the other hand, diabetes mellitus is associated with a lower FEV1. It also has been observed that wheeze, breathlessness and cough influence lungs function parameters. There were altitude-related changes in spirometric values in a group of mountaineers when spirometry was performed at the sea level and at different altitudes while anatomical differences is another factor like chest wall anatomy, lung parenchyma, lung development and mechanical properties of the thorax can be responsible for structural variations. Abdominal obesity may confine and drop diaphragm and limit lung expansion as compare to overall adiposity and visceral adipose tissues causes concentration circulating levels of cytokines (interleukin-6, tumor necrosis factor alpha, leptin and adiponectin), that act through systemic inflammation and they effect negatively to pulmonary we found that in healthy Pakistani adults it was observed that the height and age were always found to be important predictors of lung function parameters.

Researchers have linked BMI to changes in lung function relation between BMI and pulmonary function has been previously examined and BMI has been reported to be negatively associated with values for dynamic 
lung volumes including forced vital capacity (FVC) and forced expiratory volume in first second $(\mathrm{FEV} 1)^{8}$. The core features vary population to population and habitat to habitat even in the same country reference values differs, town specific reference values play vital role in studying various respiratory functions, defects leads to several maladies and spirometric variations which reveals the pulmonary function variations ${ }^{20}$. Lung function is known to vary with different ethnicity, and it is therefore important to set up normative values applicable to the ethnic group of the local population and therefore lung function values for a given ethnic group can be change over time. We conclude that FVC, FEV1, PEFR, and FEV1/FVC have significant differences in mean, the means of Baluchistan city were less than a per standard Chamanern mean values, it also gives significant differences within Citys of Baluchistan city as spirometric values exclusively depends upon body shape, chest size, BMI, Age, environment, life style, anatomical differences, altitude and lung development.

\section{Conflict of Interest}

None

\section{Acknowledgement}

None

\section{References}

1. Chavez, P. C., \& Shokar, N. K. (2009). Diagnosis and management of chronic obstructive pulmonary disease (COPD) in a primary care clinic. COPD: Journal of Chronic Obstructive Pulmonary Disease, 6(6), 446-451.

2. Guenette, J. A., Witt, J. D., McKenzie, D. C., Road, J. D., \& Sheel, A. W. (2007). Respiratory mechanics during exercise in endurance-trained men and women. The
Journal of physiology, 581(3), 13091322.

3. Sly MR. Mortality from asthma. J Allergy Clin Immunol (1989); 84:421-34. Hepper NG, Hyatt RE, Fowler WS. Detection of chronic obstructive lung disease: an evaluation of the medical history and physical examination. Arch Environ Health 1969; 19:806-13.

4. Russell, N. J., Crichton, N. J., Emerson, P. A., \& Morgan, A. D. (1986). Quantitative assessment of the value of spirometry. Thorax, 41(5), 360-363.

5. McIvor, R. A., \& Tashkin, D. P. (2001). Underdiagnosis of chronic obstructive pulmonary disease: a rationale for spirometry as a screening tool. Canadian respiratory journal, 8(3), 153-158.

6. Williams, D. E., Miller, R. D., \& Taylor, W. F. (1978). Pulmonary function studies in healthy Pakistani adults. Thorax, 33(2), 243-249.

7. Ali, B. M., \& Qureshi, R. H. (2007). Pulmonary function tests: normal values in non-smoking students and staff at the Aga Khan University, Karachi. Journal of the College of Physicians and Surgeons-Pakistan: JCPSP, 17(5), 265-268.

8. Harik-Khan, R. I., Wise, R. A., \& Fleg, J. L. (2001). The effect of gender on the relationship between body fat distribution and lung function. Journal of clinical epidemiology, 54(4), 399-406.

9. Zheng, J. P., \& Zhong, N. S. (2002). Normative values of pulmonary function testing in Chinese adults. Chinese medical journal, 115(1), 50-54.

10. Havryk, A. P., Gilbert, M., \& Burgess, K. R. (2002). Spirometry values in Himalayan high altitude residents (Sherpas). Respiratory physiology \& neurobiology, 132(2), 223-232.

11. Meysman, M., Keymeulen, B., Eeckhout, E., Noppen, M., \& Vincken, W. (2005). Spirometric changes at high altitude: the 
Shisapangma experience. Chest, 128(4), 215S-215S.

12. Miller, M. R., Crapo, R., Hankinson, J., Brusasco, V., Burgos, F., Casaburi, R., \& Jensen, R. (2005). General considerations for lung function testing. European Respiratory Journal, 26(1), 153-161.

13. Meo, S. A. (2003). Spirometric evaluation of lung function (maximal voluntary ventilation) in welding workers. Saudi medical journal, 24(6), 656-659.

14. Fulambarker, A., Copur, A. S., Javeri, A., Jere, S., \& Cohen, M. E. (2004). Reference values for pulmonary function in Asian Indians living in the United States. Chest, 126(4), 1225-1233.

15. Jones, R. L., \& Nzekwu, M. M. U. (2006). The effects of body mass index on lung volumes. Chest, 130(3), 827833.

16. Wang, M. L., McCabe, L., Hankinson, J. L., Shamssain, M. H., Gunel, E., Lapp, N. L., \& Banks, D. E. (1996). Longitudinal and cross-sectional analyses of lung function in steelworkers. American journal of respiratory and critical care medicine, 153(6), 1907-1913.

17. Ostrowski, S., Grzywa-Celinska, A., Mieczkowska, J., Rychlik, M., Lachowska-Kotowska, P., \& Lopatynski, J. (2005). Pulmonary function between 40 and 80 years of age. Journal of physiology and pharmacology, 56, 127.

18. Al-Rawas, O. A., Baddar, S., Al-Maniri, A. A., Balaji, J., Jayakrishnan, B., \& AlRiyami, B. M. (2009). Normal spirometric reference values for Omani adults. Lung, 187(4), 245-251.

19. Wu, Y., Zhang, Z., Gang, B., \& Love, E. J. (2009). Predictive equations for lung function based on a large occupational population in North China. Journal of occupational health, 51(6), 471-477.
20. Sandberg, C., \& Naylor, J. (2011). Respiratory physiology at altitude. Journal of the Royal Army Medical Corps, 157(1), 29-32. 